\title{
von Willebrand Factor and Its Propeptide in Children with Diabetes. Relation between Endothelial Dysfunction and Microalbuminuria
}

\author{
ALBERTO VERROTTI, RITA GRECO, FANIA BASCIANI, GUIDO MORGESE, AND \\ FRANCESCO CHIARELLI \\ Department of Medicine, Section of Pediatrics, University of Chieti, Chieti, Italy [A.V., R.G., F.B., F.C.], \\ and Department of Pediatrics, University of Siena, Siena, Italy [G.M.]
}

\begin{abstract}
ABST
It has been shown that patients with insulin-dependent dia-
betes mellitus have elevated von Willebrand factor (vWF)
plasma concentrations. Plasma fibrinogen, vWF, and its propep-
tide concentrations have been evaluated in 102 children with
insulin-dependent diabetes mellitus to determine whether an
increase of vWF and its propeptide levels precedes and may
predict the development of persistent microalbuminuria. The
patients have been divided into two groups according to the
presence or absence of microalbuminuria at the end of follow-up.
They have been followed up for at least 8 y. Control group
consisted of 80 age- and sex-matched healthy volunteers. At the
beginning of the study there was no significant difference in
fibrinogen, vWF, and its propeptide levels between patients and
control subjects. During the follow-up, a significant increase of
plasma vWF and its propeptide has been observed in the group of
patients who later developed microalbuminuria but not in those
\end{abstract}
Vascular complications are the main causes of morbidity and mortality in patients with diabetes. It has been very well established that microalbuminuria is defined as an abnormally elevated AER below the level of clinical albuminuria; this represents a urinary albumin excretion rate of $20-200 \mu \mathrm{g} / \mathrm{min}$, equal to $30-300 \mathrm{mg} / 24 \mathrm{~h}$ (1). In patients with IDDM, microalbuminuria predicts the development not only of diabetic nephropathy but also of macrovascular disease $(2,3)$.

There are several indications that endothelial damage could play a key role in the development of both micro- and macroangiopathy (4). The endothelium is an important locus of control of vascular functions. It actively regulates vascular tone and permeability, the balance between coagulation and fibrinolysis, the composition of the subendothelial matrix, and the mitogenesis of vascular smooth muscle and renal mesangial

Received October 16, 2001; accepted April 26, 2002.

Correspondence: Alberto Verrotti, M.D., Ph.D., Department of Pediatrics, University of Chieti, Ospedale Policlinico, Via dei Vestini 5, 66013 Chieti, Italy; e-mail: chiarelli (a) unich.it

DOI: 10.1203/01.PDR.0000049509.65496.BF who remained normoalbuminuric. This increase started 3 y and become statistically significant $(p<0.01) 2$ y before the onset of microalbuminuria, persisting until the end of the study. During the entire follow-up plasma values of fibrinogen persisted in the normal range. In conclusion, an increase in plasma concentration of $\mathrm{vWF}$ and its propeptide precedes microalbuminuria and, therefore, can be useful to identify children with insulin-dependent diabetes mellitus at risk to develop incipient nephropathy later in life. (Pediatr Res 53: 382-386, 2003)
Abbreviations
AER, albumin excretion rate
IDDM, insulin-dependent diabetes mellitus
vWF, von Willebrand factor
vWF propeptide, von Willebrand factor propeptide
HbA1c, glycated $\mathrm{Hb}$

cells (5-7). It has been shown that there is a close association between microalbuminuria and endothelial dysfunction $(2,3,8)$.

Thus, in patients with microalbuminuria, the vascular endothelium tends to increase vascular resistance $(9,10)$, fails to restrict the passage of macromolecules $(2,3,8)$, and loses its anticoagulant and profibrinolytic properties $(11,12)$. In adult patients with diabetic nephropathy, a significant increase in plasma concentration of markers of endothelial injury and dysfunction, such as $\mathrm{vWF}$, a glycoprotein involved in primary hemostasis and secreted mainly by endothelial cells and megakaryocytes, has been shown $(11,13)$.

Some authors have suggested that measuring vWF can have a role in the prediction of risk for development of nephropathy $(14,15)$, whereas others did not confirm this hypothesis $(16$, 17). vWF is synthesized as a large $360-\mathrm{kD}$ precursor, named pro-vWF. After many changes in the endoplasmic reticulum and the Golgi apparatus, this precursor undergoes cleavage into mature vWF and a large 97-kD propeptide. Stimulation of exocytosis causes the release of equimolar amounts of $\mathrm{vWF}$ and propeptide. It has been suggested (18) that concomitant determinations of plasma vWF and its propeptide are useful 
tools to assess endothelial activation in vivo, but there is no study in which the levels of propeptide have been evaluated in diabetic children.

The aims of the present study were to evaluate whether endothelial dysfunction precedes the occurrence of microalbuminuria and whether it can help to identify those patients who are at risk to develop microalbuminuria.

\section{METHODS}

Subjects. One hundred eleven IDDM patients (52 girls and 59 boys) were recruited prospectively from the Department of Pediatrics, University of Chieti. During the study nine of 111 children showed intermittent microalbuminuria (defined as AER $>20 \mu \mathrm{g} / \mathrm{min}$ in one of three overnight urine collections in the last $6 \mathrm{mo}$ and with a persistence of normoalbuminuria in the next years), and for this reason we excluded them from the study. Therefore, the evaluation was performed on the remaining 102 children. Their age ranged from 8.1 to $12.9 \mathrm{y}$ with a duration of diabetes of 4.0 to $9.9 \mathrm{y}$. Inclusion criteria for study participation were absence of other metabolic diseases and normal liver and renal function tests, absence of any medication (including nonsteroidal antiinflammatory drugs or angiotensin-converting enzyme inhibitors), use of no medication other than insulin, duration of disease longer than $5 \mathrm{y}$, and normal blood pressure. The exclusion criteria were diabetic retinopathy on fluorescein angiography, presence of microalbuminuria and nephropathy, and electrophysiologic abnormalities of autonomic or peripheral neuropathy. Patients were divided into two groups according to the presence or absence of microalbuminuria at the end of follow-up. No patient smoked at the beginning of the study and during the whole follow-up. Control group consisted of 80 age- and sex-matched healthy volunteers. They did not receive any drug before blood collection. Clinical and laboratory data were obtained at baseline (baseline evaluation) and during $8 \mathrm{y}$ of follow-up (follow-up evaluation). Clinical (diabetes duration, blood pressure, insulin dose) as well as laboratory data (glucose, fibrinogen, vWF, vWF propeptide, HbAlc, serum creatinine concentration, AER) were evaluated. At the beginning of the study there were no differences between the two groups of patients in age, sex, duration of diabetes, and serum creatinine (Table 1).

During the study, patients did not undergo antihypertensive therapy and did not show clinical or biochemical evidence of renal disease. At the beginning of the study all patients showed an AER $<20 \mu \mathrm{g} / \mathrm{min}$ in three overnight urine collections obtained over 6 mo. We defined persistent microalbuminuria as

Table 1. Pertinent data of the two groups of diabetic patients and of control subjects

\begin{tabular}{lccc}
\hline & Group A & Group B & Control Group \\
\hline Age $(\mathrm{y})$ & $10.9 \pm 2.1$ & $10.4 \pm 2.3$ & $12.8 \pm 2.7$ \\
Sex $(\mathrm{M} / \mathrm{F})$ & $41 / 42$ & $11 / 8$ & $54 / 48$ \\
Duration of diabetes $(\mathrm{y})$ & $6.9 \pm 3.0$ & $6.0 \pm 3.9$ & - \\
AER $\left(\mu \mathrm{g} / \mathrm{min} / 1.73 \mathrm{~m}^{2}\right)$ & $8.3 \pm 2.9$ & $9.7 \pm 2.7$ & $7.3 \pm 1.9$ \\
HbA1c $(\%)$ & $7.4 \pm 1.5$ & $7.9 \pm 1.9$ & $4.7 \pm 0.9$ \\
Serum creatinine $(\mu \mathrm{mol} / \mathrm{L})$ & $72.1 \pm 19.4$ & $74.8 \pm 20.1$ & $71.1 \pm 18.1$ \\
\hline
\end{tabular}

an AER $>20 \mu \mathrm{g} / \mathrm{min}$ in two of three consecutive overnight urine collections. All patients had normal blood pressure values. The informed consent of study has been obtained from the parents of all patients studied; consent was obtained also in the control group. The study was approved by the Ethical Committee of the Faculty of Medicine, University of Chieti, Italy.

Methods. AER was measured by an ELISA technique (19), and the annual level was determined as the mean of AER in three overnight urine collections taken at home during normal physical activity. The interassay and intraassay variations of AER measurement were 8.3 and $2.1 \%$, respectively. Plasma fibrinogen and vWF were measured centrally on citrated plasma prepared from fresh blood obtained by venepuncture. Plasma samples were stored at $-20^{\circ} \mathrm{C}$ at all times until assay. Fibrinogen was assayed by a clotting assay based on the prothrombin time, on an Instrumentation Laboratories Series 300 Autoanalyzer, and vWF antigen was assayed by ELISA, as previously described (20); a pooled plasma standard, calibrated against the U.K. (NIBSAC) standard, was used. vWF propeptide was measured by a method described in detail previously (21). Briefly, 96-well plates were coated with the MAb BR5 and $3 \mathrm{H} 4,0.75 \mu \mathrm{g} / \mathrm{mL}$ each in carbonate buffer $\left(\mathrm{NaHCO}_{3}, 50\right.$ $\mathrm{mM}, \mathrm{pH}$ 9.6). After blocking of the remaining protein binding sites with 5\% (wt/vol) dry skim milk, the samples and standards diluted in blocking solution were added and incubated for $2 \mathrm{~h}$ at $37^{\circ} \mathrm{C}$. The bound antigen was detected with a third antipropeptide MAb (8H10) conjugated to alkaline phosphatase diluted 1:800 (approximately $0.25 \mu \mathrm{g} / \mathrm{mL}$ ). Alkaline phosphatase activity was detected using $p$-nitrophenyl phosphate as a substrate and measuring the OD at $405 \mathrm{~nm}$. Using purified plasma propeptide as a standard, we determined the propeptide concentration in normal pooled plasma at $720 \pm 43 \mathrm{ng} / \mathrm{mL}$ (mean $\pm \mathrm{SEM}, n=5$ ). For routine assays, a standard curve was constructed with normal pooled plasma. Each sample was tested at four dilutions of 1:320-1:640, which corresponds to a sensitivity of $<2.5 \mathrm{ng} / \mathrm{mL}(<25 \mathrm{pmol} / \mathrm{L}$, assuming a molecular weight of $97 \mathrm{kD}$ ).

HbA1c was measured by HPLC (DIAMAT; Bio-Rad, Richmond, CA, U.S.A.). The normal range was $4.1 \pm 1.4 \%$. Blood pressure was measured by a standard clinical sphygmomanometer on the right arm after a 10-min supine rest. Serum creatinine was measured by Jaffe's method to exclude pseudocreatinine. Glucose was determined instantaneously by the glucose oxidase-based method (YSI, Yellow Springs, OH, U.S.A.) in arterial whole blood.

Statistical analysis. Data are presented as mean \pm SD or medians with ranges. $\chi^{2}$ tests, two-tailed $t$ test, or the MannWhitney nonparametric test was used to assess the degree of statistical significance of differences. In particular, the two groups were compared with regard to laboratory characteristics and changes therein at each examination using standard parametric and nonparametric testing as indicated by Bonferroni's test.

Pearson's coefficients were calculated for correlation analyses. Probability values $<5 \%$ were considered statistically significant. All analyses were run on a personal computer with the statistics package SPSS for Windows version 5.0. 


\section{RESULTS}

Baseline evaluation. At the beginning of the study, patients with IDDM showed normal AER $(<20 \mu \mathrm{g} / \mathrm{min})$. Fibrinogen, $\mathrm{vWF}$, and $\mathrm{vWF}$ propeptide values were similar to controls, and there were no significant differences for all variables studied.

Follow-up evaluation. During 8 y and at the end of followup, 19 of the 102 patients $(18.6 \%)$ developed persistent microalbuminuria. An increase of plasma vWF and vWF propeptide levels was observed in patients who later developed microalbuminuria (group B) compared with those who remained normoalbuminuric (group A; Figs. 1 and 2). This increase started $3 \mathrm{y}$ and become statistically significant $(p<$ 0.01) 2 y before the onset of persistent microalbuminuria, persisting until the end of the study. In detail, at the end of the study, in group A we observed six of 83 children who had vWF and its propeptide higher than $170 \mathrm{U} / \mathrm{L}$ and $175 \%$, respectively; in group B two of 19 patients who had vWF and its propeptide lower than $170 \mathrm{U} / \mathrm{L}$ and $175 \%$, respectively. The positive predictive value was $89.5 \%$, and the negative predictive value was $88.0 \%$.

The increase of AER was more evident during the pubertal development of these patients. Moreover, nine of the 19 patients showed the development of background and preproliferative retinopathy (four and five patients, respectively) evaluated by fluorescence angiography.

During the entire period of the study, plasma values of fibrinogen persisted in the normal range both in microalbuminuric and in normoalbuminuric patients (Fig. 3).

In both groups a significant increase of $\mathrm{HbAlc}$ values was observed at the end of the study (Fig. 4). Values of AER during the study are shown in Figure 5.

To evaluate the relationship between age, diabetes duration, sex, $\mathrm{HbAlc}$, blood pressure, and onset of microalbuminuria or retinopathy and fibrinogen, $\mathrm{vWF}$, and its propeptide levels, we performed a multivariate analysis (ANOVA): no significant relationship was found.

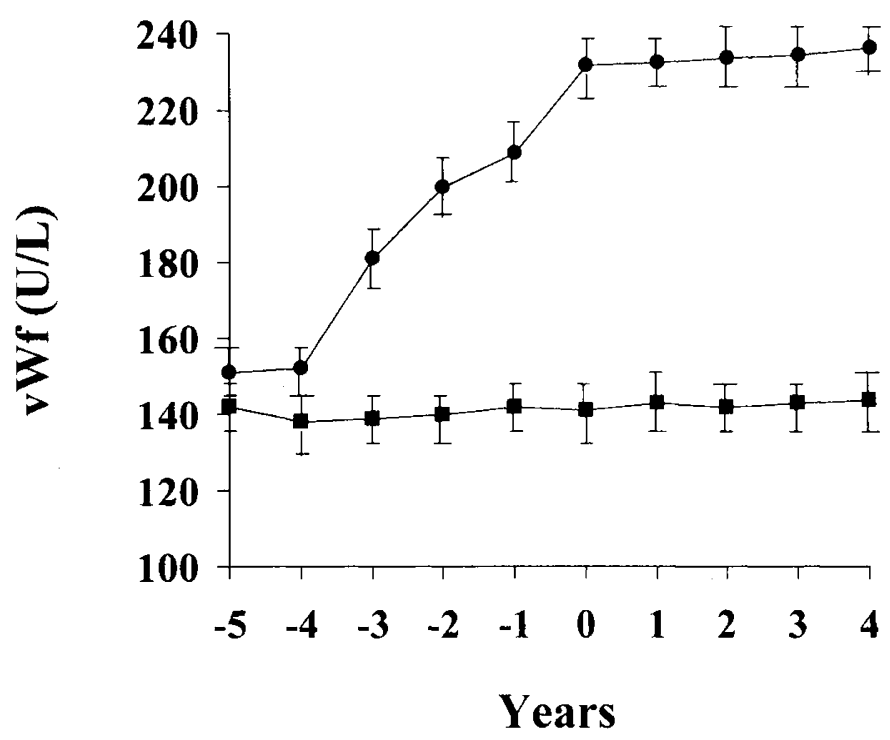

Figure 1. Plasma vWF levels in group A ( $\square$ ) and group B $(\bullet)$ patients. Year 0 is the year of the beginning of persistent microalbuminuria.

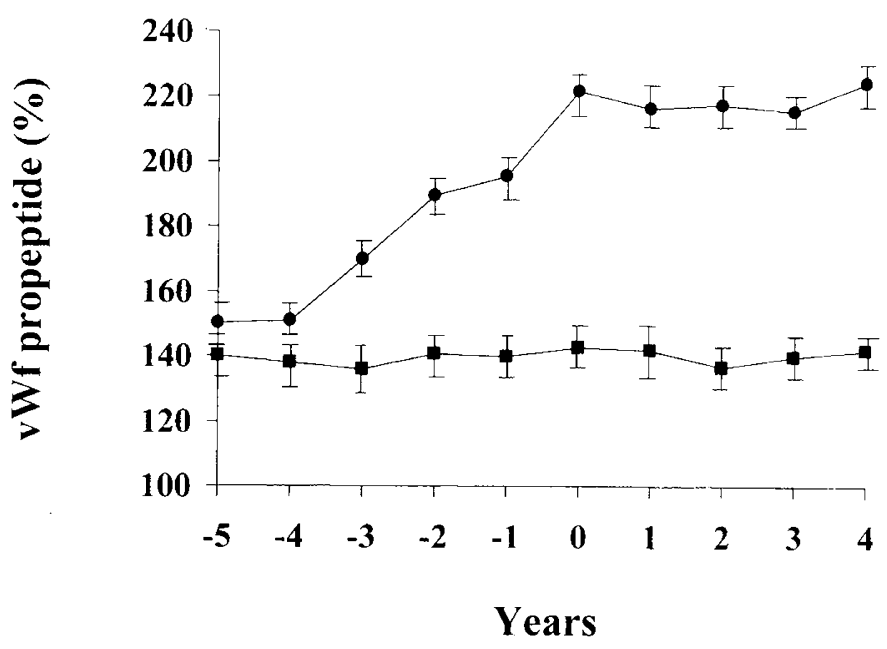

Figure 2. Plasma vFW propeptide levels in group A ( $\square$ ) and group B (०) patients. Year 0 is the year of the beginning of persistent microalbuminuria.

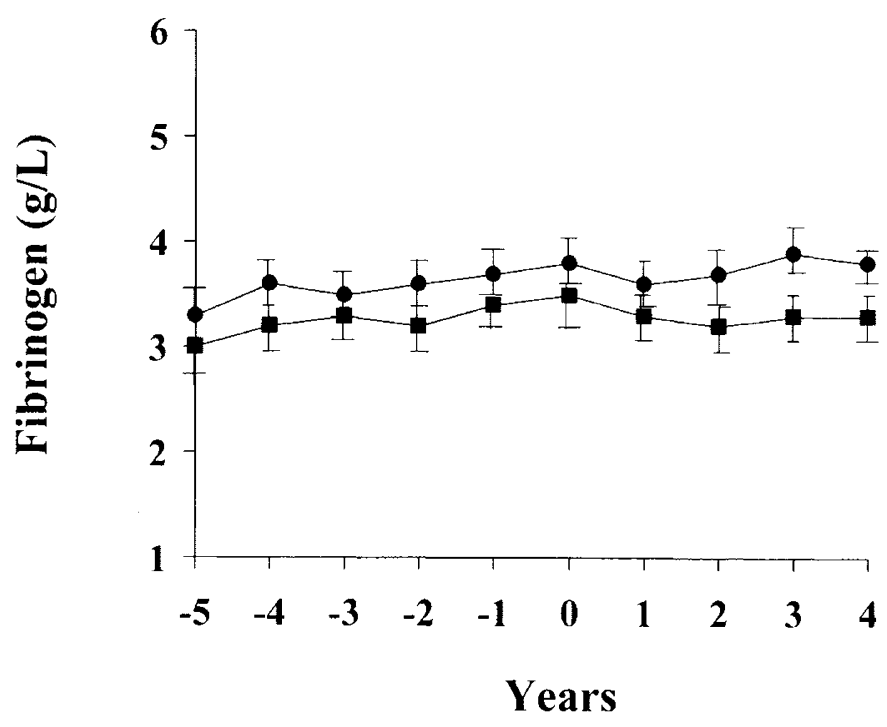

Figure 3. Plasma fibrinogen levels in group A $(\square)$ and group B $(\bullet)$ patients. Year 0 is the year of the beginning of persistent microalbuminuria.

\section{DISCUSSION}

Injury to the vascular endothelium appears to be central to the pathogenesis of atherosclerosis and may be an initiating event. Endothelial dysfunction is also a feature of diabetic nephropathy, even during the subclinical phase.

It has recently been shown that adult IDDM patients with albuminuria have elevated $\mathrm{vWF}$ and fibrinogen plasma concentrations $(15,18)$. In the present follow-up study, we found an association between the increases of AER, vWF, and its propeptide before the development of persistent microalbuminuria by as much as $2 \mathrm{y}$.

vWF and vWF propeptide are released in equimolar amounts; parallel determination of plasma vWF and its propeptide can help to differentiate between increased endothelial secretion and alterations in vWF catabolism (18). We measured both $\mathrm{vWF}$ and $\mathrm{vWF}$ propeptide, demonstrating that endothelial dysfunction is present at least 2 y before the development of persistent microalbuminuria. Some authors 


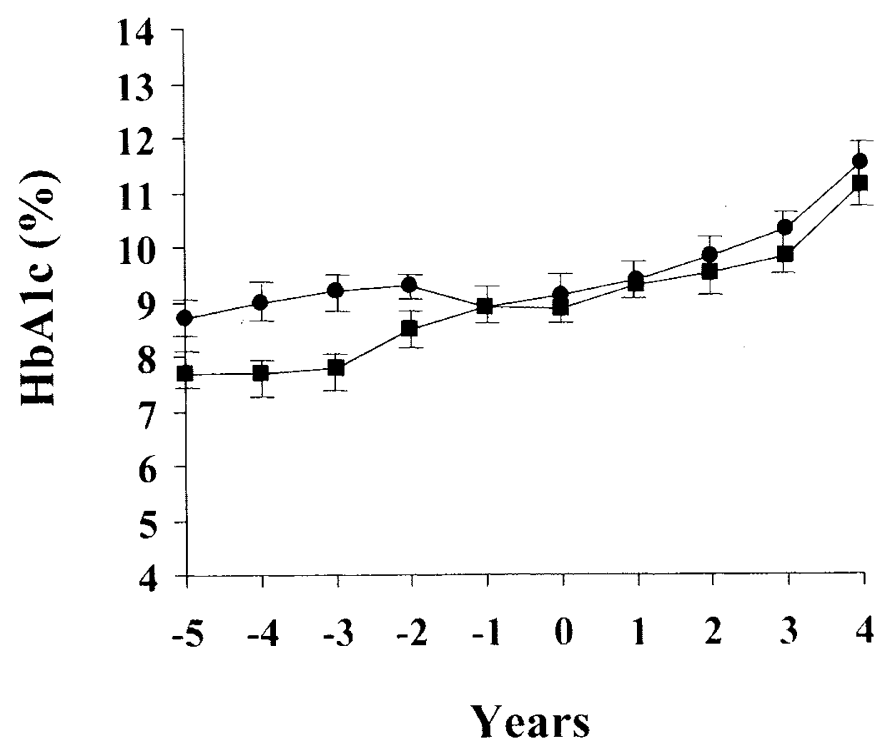

Figure 4. HbAlc percentages in group A $(\square)$ and group B $(\bullet)$ patients. Year 0 is the year of the beginning of persistent microalbuminuria.

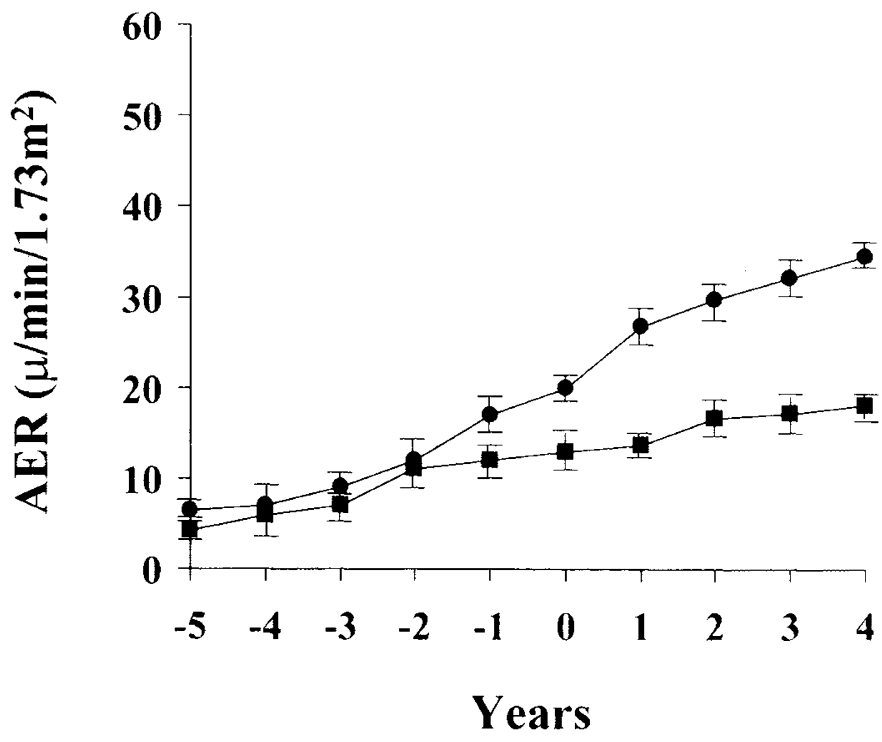

Figure 5. AER values in group A $(\square)$ and group B $(\bullet)$ patients. Year 0 is the year of the beginning of persistent microalbuminuria.

$(18,21)$ suggested that in conjunction with vWF, vWF propeptide may improve the identification of endothelial activation; our data suggest that vWF propeptide concentrations do not increase earlier than vWF values before the onset of microalbuminuria, but its increase is simultaneous to the increase of vWF concentrations. Therefore, the parallel determination of vWF and $\mathrm{vWF}$ propeptide does not add any useful information for the early prediction of the development of microalbuminuria.

Stehouwer et al. (14) reported that the increase in plasma $\mathrm{vWF}$ precedes and may therefore help to predict the development of microalbuminuria in IDDM. More recently, Greaves et al. (15) found a positive relationship among fibrinogen, $v W F$, and AER in those with retinopathy but not in those without retinopathy. These findings are consistent with the hypothesis that microalbuminuria and increased $\mathrm{vWF}$ and vWF propeptide are related to endothelial cell perturbation in response to mildly raised blood pressure in subjects with retinopathy. Fibrinogen may also contribute to microvascular disease, and its relationship to lipid vascular risk factors suggests a possible pathogenetic role in vascular complications of diabetes.

Endothelial dysfunction in microalbuminuric IDDM patients appears to be generalized in that it affects many aspects of endothelial function $(2,8,9,11,22)$. We suggest that endothelial dysfunction in IDDM develops gradually, with sustained increases in plasma vWF, its propeptide, and AER as relatively advanced features.

The type of endothelial dysfunction reflected by increased vWF and fibrinogen levels is closely related to microalbuminuria not only in IDDM (13) but also in non-insulin-dependent diabetes mellitus $(22,23)$ and essential hypertension (24), although all our patients remained normotensive until the end of follow-up.

It is not clear, however, whether the prognostic value of $\mathrm{vWF}$ and vWF propeptide is related to their specific functions, i.e. enhancement of platelet adhesion and factor VIII availability, or whether they are simply markers of endothelial injury and dysfunction. Nevertheless, vWF, vWF propeptide, and AER deserve consideration as clinically useful markers of vascular status.

It has long been recognized that plasma fibrinogen concentrations are elevated in diabetes (4) but a relationship with nephropathy has not always been apparent (11). Fibrinogen could contribute to the development of nephropathy in a variety of ways: it is the substrate for thrombin in blood coagulation, and animal studies indicate that the fibrinogen concentration at the initiation of coagulation influences the amount of fibrin deposited (14). Our study demonstrates that fibrinogen does not increase in patients who develop microalbuminuria.

\section{CONCLUSION}

In conclusion, the present data show that in adolescents and young adults with onset of diabetes during childhood, endothelial dysfunction, evaluated as vWF and vWF propeptide, precedes the development of microalbuminuria and may help to identify patients with onset of diabetes during childhood at risk to develop diabetic nephropathy later in life.

\section{REFERENCES}

1. Parving HH 1996 Microalbuminuria in essential hypertension and diabetes mellitus. J Hypertens 14(suppl 2):89-94

2. Jensen T 1991 Albuminuria: a marker of renal and generalized vascular disease in insulin-dependent diabetes mellitus. Dan Med Bull 38:134-144

3. Messent JWC, Elliott TG, Hill RD, Jarrett RJ, Keen H, Viberti GC 1992 Prognostic significance of microalbuminuria in insulin-dependent diabetes mellitus: a twentythree year follow-up study. Kidney Int 41:836-839

4. Huvers FC, De Leeuw PW, Houben AJHM, De Haan CHA, Hamulyak K, Schouten H, Wolffenbuttel BHR, Schaper NC 1999 Endothelium dependent vasodilatation, plasma markers of endothelial function, and adrenergic vasoconstrictor responses in type I diabetes under near-normoglycemic conditions. Diabetes 47:1300-1307

5. Vane JR, Anggard EE, Botting RM 1990 Mechanism of disease: regulatory functions of the vascular endothelium. N Engl J Med 323:27-36

6. Ross R 1993 The pathogenesis of atherosclerosis: a perspective for the 1990s. Nature 362:801-809

7. Remuzzi G, Benigni A 1993 Endothelins in the control of cardiovascular and renal function. Lancet 342:589-593 
8. Deckert T, Feldt-Rasmussen B, Borch-Johnsen K, Jensen T, Kofoed-Enevoldsen A 1989 Albuminuria reflects widespread vascular damage: the Steno hypothesis. Diabetologia 32:219-226

9. Elliott TG, Cockcroft JR, Groop PH, Viberti GC, Ritter JM 1993 Inhibition of nitric oxide synthesis in forearm vasculature in insulin-dependent diabetic patients: blunted vasoconstriction in patients with microalbuminuria. Clin Sci 83:687-693

10. Collier A, Leach JP, McLellan A, Jardine A, Morton JJ, Small M 1992 Plasma endothelinlike immunoreactivity levels in IDDM patients with microalbuminuria. Diabetes Care 15:1038-1040

11. Jensen T, Bjerre-Knudsen J, Feldt-Rasmussen B, Deckert T 1989 Features of endothelial dysfunction in early diabetic nephropathy. Lancet 1:461-463

12. Gruden G, Cavallo-Perin P, Bazzab M, Stella S, Vuolo A, Pagano G 1994 PAI-1 and factor VII activity are higher in insulin-dependent diabetes mellitus patients with microalbuminuria. Diabetes 43:426-429

13. Stehouwer CDA, Stroes ESG, Hackeng WHL, Mulder PGH, den Ottolander GJH 1991 von Willebrand factor and development of diabetic nephropathy in insulindependent diabetes mellitus. Diabetes 40:971-976

14. Stehouwer CDA, Fischer HRA, van Kuijk AWR, Polak BCP, Donker AJM 1995 Endothelial dysfunction precedes development of microalbuminuria in IDDM. Diabetes 44:561-564

15. Greaves M, Malia RG, Goodfellow K, Mattock M, Stevens LK, Stephenson JM, Fuller JH, Eurodiab IDDM Complications Study Group 1997 Fibrinogen and von Willebrand factor in IDDM: relationships to lipid vascular risk factor, blood pressure, glycaemic control and urinary albumin excretion rate: the Eurodiab IDDM Complications Study. Diabetologia 40:698-705

16. Myrup B, Mathiesen ER, Ronn B, Deckert T 1994 Endothelial function and serum lipids in the course of developing microalbuminuria in insulin-dependent diabetes mellitus. Diabetes Res 26:33-39
17. Jensen JS, Myrup B, Borch-Johnsen K, Jensen G, Jensen T, Feldt-Rasmussen B 1995 Aspects of haemostatic function in healthy subjects with microalbuminuria - a potential atherosclerotic risk factor. Thromb Res 77:423-430

18. Vischer UM, Emeis JJ, Bilo HJG, Stehouwer CDA, Thomsen C, Rasmussen O, Hermansen K, Wollheim CB, Ingerslev J 1998 von Willebrand factor (vWf) as a plasma marker of endothelial activation in diabetes: improved reliability with paralle determination of the vWf propeptide (vWf: AgII). Thromb Haemost 80:1002-1006

19. Feldt-Rasmussen B, Dinesen B, Deckert M 1985 Enzyme immunoassay: an improved determination of urinary albumin excretion in diabetics with incipient nephropathy. Scand J Lab Clin Invest 45:539-544

20. Ford I, Malik RA, Newrick PG, Preston FE, Ward JD, Greaves M 1992 Relationships between haemostatic factors and capillary morphology in human diabetic neuropathy. Thromb Haemost 68:628-633

21. Vischer UM, Ingerslev J, Wollheim CB, Mestries JC, Tsakiris DA, Haefeli WE, Kruithof EK 1997 Acute von Willebrand factor secretion from the endothelium in vivo: assessment through plasma propeptide (vWf:AgII) levels. Thromb Haemost 77:387-393

22. Stehouwer CDA, Donker AJM 1993 Urinary albumin excretion and cardiovascular disease risk in diabetes mellitus: is endothelial dysfunction the missing link? J Nephrol 6:72-92

23. Stehouwer CDA, Nauta JJP, Zeldenrust GC, Hackeng WHL, Donker AJM, den Ottolander GJH 1992 Urinary albumin excretion, cardiovascular disease, and endothelial dysfunction in non-insulin-dependent diabetes mellitus. Lancet 340:319-323

24. Pedrinelli R, Giampietro O, Carnassi F, Mellilo E, Dell'Omo G, Catapano G, Matteuci E, Talarico L, Morale M, de Negri F, di Bello V 1994 Microalbuminuria and endothelial dysfunction in essential hypertension. Lancet 344:14-18 